\title{
Injection Molding of Wood-Filled Thermoplastic Polyurethane
}

\author{
Elmar Moritzer and Maximilian Richters *(D) \\ Faculty of Engineering, Kunststofftechnik Paderborn (KTP), University of Paderborn, Warburger Straße 100, \\ 33098 Paderborn, Germany; elmar.moritzer@ktp.upb.de \\ * Correspondence: maximilian.richters@ktp.upb.de
}

check for

updates

Citation: Moritzer, E.; Richters, M. Injection Molding of Wood-Filled Thermoplastic Polyurethane. J. Compos. Sci. 2021, 5, 316. https:// doi.org/10.3390/jcs5120316

Academic Editor: Aleksander Hejna

Received: 11 November 2021 Accepted: 27 November 2021 Published: 30 November 2021

Publisher's Note: MDPI stays neutral with regard to jurisdictional claims in published maps and institutional affiliations.

Copyright: (c) 2021 by the authors. Licensee MDPI, Basel, Switzerland. This article is an open access article distributed under the terms and conditions of the Creative Commons Attribution (CC BY) license (https:/ / creativecommons.org/licenses/by/ $4.0 /)$.

\begin{abstract}
Wood fiber reinforcement of plastics is almost limited to polypropylene, polyethylene, polyvinyl chloride and polystyrene. Wood fiber reinforcement of thermoplastic polyurethanes (TPU) is a new research field and paltry studied scientifically. Wood fiber reinforcement can carry out synergistic effects between sustainability, material or product price reduction, improved mechanical properties at high elongation, and brilliant appearance and haptics. In order to evaluate to what extent the improvement of mechanical properties depend on material-specific parameters (fiber type, fiber content) and on process-specific parameters (holding pressure, temperature control and injection speed), differently filled compounds were injection molded according to a partial factorial test plan and subjected to characterizing test procedures (tensile test, Shore hardness and notched impact test). Tensile strength showed significant dependence on barrel temperature, fiber type and interaction between holding pressure and barrel temperature in the region of interest. Young's modulus can be influenced by fiber content but not by fiber type. Notched impact strength showed a significant influence of cylinder temperature, fiber content, fiber type and the interaction between cylinder temperature and fiber content in the region of interest. Shore hardness is related to fiber content and the interaction between mold temperature and injection flow rate. Our results show not only that wood-filled TPU can be processed very well by injection molding, but also that the mechanical properties depend significantly on temperature control in the injection-molding process. Moreover, considering the significant reinforcing effect of the wood fibers, a good fiber-matrix adhesion can be assumed.
\end{abstract}

Keywords: wood-plastic composites; wood; thermoplastic polyurethane; TPU; WPC; injection molding

\section{Introduction}

In the context of sustainability, natural fiber-reinforced plastics [1,2] such as woodplastic composites (WPC) [3] are gaining an important role in plastics processing due to their low dependence on fossil resources and their lower $\mathrm{CO}_{2}$ footprint compared to inorganically reinforced plastics or pure plastics [4]. Currently, the most established manufacturing process is the extrusion of continuous WPC products. Continuous products such as decking boards or palisades are extremely popular due to their durability and weather resistance. Consumer goods such as toothbrushes, furniture or technical parts for the automotive industry represent a large market potential for WPC injection-molded parts, which stand out due to their brilliant look and feel [5]. Common matrix materials for processing are polyolefins such as polyethylene $(\mathrm{PE})$ and polypropylene $(\mathrm{PP})$ because of the low price and low penetrability for water $[3,6,7]$. The decisive factor for selecting matrix materials is their specific melting point. Ideally, the melting point should be below $200{ }^{\circ} \mathrm{C}$ since wood fibers or their molecular components start to decompose at higher temperatures [8-14]. These decomposition processes can significantly reduce the mechanical properties of WPCs. Another challenge in WPC processing is poor fiber/matrix adhesion. During compounding, polar fibers encounter a nonpolar matrix material. Polar means a charge shift is existing in the molecular chain and a dipole is formed, whereas nonpolar materials do not form a dipole in the molecular chain. This physicochemical 
discrepancy results in poor fiber/matrix adhesion and low mechanical properties. This can be remedied by acetylation or salinization of the fibers or by adding coupling agents, such as maleic acid-grafted polypropylene [15-18]. Furthermore, the particle size has a critical effect on tensile strength. Sälzer et al. found an optimum in tensile strength for particle sizes of $500 \mu \mathrm{m}$, and for particle sizes smaller and larger than $500 \mu \mathrm{m}$, they observed a decrease in tensile strength across all fibers or wood type [19]. Siwek et al. provided similar results through investigations on compounds produced by a heating-cooling mixer [20].

Radovanovic demonstrated that the behavior of WPC in the injection-molding process is not trivial. The increase of the wood content from $50-\mathrm{wt}-\%$ to $70-\mathrm{wt}-\%$ leads to an increase of the injection pressure by $50 \%$. Furthermore, by varying the matrix material, it was found that the fibers are responsible for the increase in strength and elastic modulus, while the matrix material has a minor influence. In addition, a significant negative influence of water absorption on tensile strength was found with increasing fiber content [21]. Schröder also found that the processing behavior of WPCs is complex. WPC with a wood content of more than $30-w t-\%$ exhibited different flow and filling properties compared to standard plastics. In the case of cavities with low geometric freedom, stagnation of the melt occurred. The melt solidified in the first third of the flow path and the cavity was completely filled up to this point. Subsequently, the injection pressure is strong enough and the melt front continues. For cavities with large geometric freedom, flow front breaks up so that the cavity is filled irregularly and not under headstream. In addition, it has been shown by Soxhlet extraction that segregation between the fibers and the matrix occurs at long flow paths $[22,23]$. Based on the molecular structure, it can be assumed that the polarity of thermoplastic polyurethane (TPU) leads to increased fiber-matrix adhesion. Hydrogen bonds are formed between the cyano-group of the TPU and the hydroxy group of the wood fibers [24-26].

In the field of wood filling of thermoplastic elastomers or thermoplastic polyurethanes, only a few publications have surfaced so far. Diestel \& Krause conducted studies on the water absorption of wood-filled TPU compounded in a compression molding process utilizing a heating-cooling mixer [27]. Kilinc et al. conducted similar studies on injectionmolded test specimens with respect to the functionalization of wood fibers [28]. Mengeloglu \& Cavus performed studies on the filling of ester-based TPU with teak, rice husks and microcrystalline cellulose. Using injection-molded specimens, the authors found that the increase in density was significantly dependent on filler content and filler material. Moreover, an increase in tensile strength was observed for TPU filled with microcrystalline cellulose, whereas, for other compounds, a decrease in tensile strength was observed above a fiber content of 30-wt-\%. An increase of the Young's modulus was observed as a function of the fiber content, but not with regard to the filler [29]. Here, we investigate the processability of wood-filled thermoplastic polyurethanes by injection molding, in order to define a suitable parameterization and to record the mechanical properties of wood-filled TPU.

\section{Materials and Methods}

\subsection{Wood Fiber}

Arbocel C320 and Lignocel BK 40-90 (J. Rettenmaier \& Söhne GmbH + Co. KG, Rosenberg, Germany) fiber types were used as fillers for the production of the WPC compounds. Arbocel C320 $(200-500 \mu \mathrm{m})$ is a raw cellulose and Lignocel BK 40-90 $(1000-2000 \mu \mathrm{m})$ a softwood blend (Figure 1).

\subsection{Thermoplastic Elastomers}

The matrix material used was Desmopan ${ }^{\circledR}$ 6064A (Covestro Deutschland AG, Leverkusen, Germany) from the thermoplastic polyurethane (TPU) material class. In Desmopan ${ }^{\circledR} 6064 \mathrm{~A}$, the soft segment is based on an ether compound. With a Shore hardness of 67A (1 s), the suitable processing temperature is between 200 and $220^{\circ} \mathrm{C}$. 


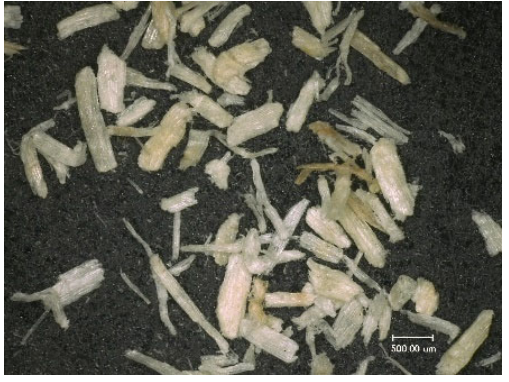

(a)

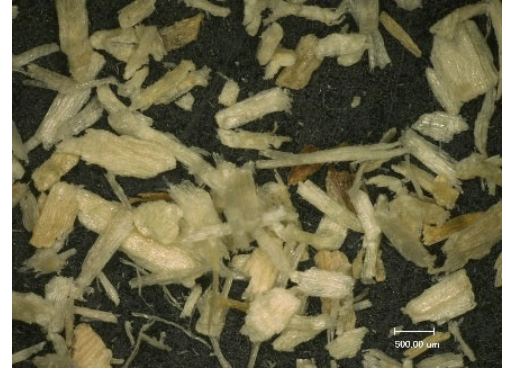

(b)

Figure 1. (a) Microscope image of Arbocel C320. (b) Microscope image of Lignocel BK40/90.

\subsection{Drying}

Due to their hygroscopic material behavior, the compounds were dried for 8-12 $\mathrm{h}$ depending on the fiber content (20-40-wt-\%). To protect the wood fibers from thermal degradation, a temperature of $80{ }^{\circ} \mathrm{C}$ and a drying volume flow of $14 \mathrm{~m}^{3} / \mathrm{h}$ were not exceeded.

\subsection{Injection Molding}

The test specimens (Figure 2) were manufactured on a 420C Golden Edition injection molding machine from ARBURG GmbH \& Co. KG. The test specimen geometry (1A) was used according to DIN EN ISO 527-2.

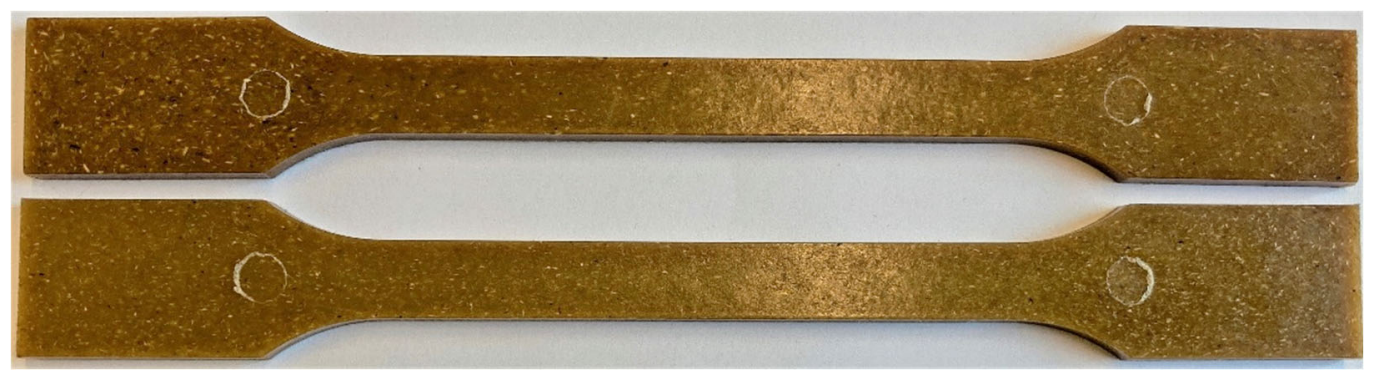

Figure 2. Test specimens of wood-filled TPU. Top: TPU with 30-wt-\% Lignocel BK40/90, bottom: 30-wt-\% Arbocel C320.

An experimental design with the following parameters was created using Design Expert 12 from Stat-Ease Inc. (Table 1). The Response-Surface study type was selected. D-optimal was selected as the design type, resulting in a trial design with 40 test points. A quadratic model was preferred for the analysis of the experimental design in order to analyze the interaction between parameters. The significance level chosen was $p<0.05$.

Table 1. Parameters for the experimental setup. The parameters were varied in factor levels I-III.

\begin{tabular}{ccccc}
\hline Parameter & Unit & Factor I & Factor II & Factor III \\
\hline Nozzle temperature ${ }^{1}\left(T_{\text {nozzle }}\right)$ & ${ }^{\circ} \mathrm{C}$ & $-\mathbf{1}$ & $\mathbf{0}$ & $\mathbf{+ 1}$ \\
Mold temperature $\left(T_{\text {mold }}\right)$ & ${ }^{\circ} \mathrm{C}$ & 190 & 200 & 210 \\
\hline Injection flow rate $\left(\dot{V}_{\text {in }}\right)$ & $\mathrm{cm}^{3} / \mathrm{s}$ & 30 & 60 & 70 \\
Holding pressure $(p)$ & $\mathrm{bar}$ & 500 & 40 & 50 \\
\hline Fiber content $(F C)$ & $\%$ & 20 & 300 & 700 \\
Fiber type $(F T)$ & & Arbocel C320 & Lignocel BK 40/90 \\
\hline
\end{tabular}

${ }^{1}$ For the injection-molding unit, a temperature profile was set in $10{ }^{\circ} \mathrm{C}$ increments between the feeder and the nozzle. The target value was the respective nozzle temperature. 


\subsection{Tensile Test}

The tensile tests were carried out in accordance with DIN EN ISO 527-2. The preload was $10 \mathrm{~N}$ and the test speed $50 \mathrm{~mm} / \mathrm{min}$. To measure the modulus of elasticity, the stress gradient was measured between $0.05 \%$ and $0.25 \%$ at a speed of $1 \mathrm{~mm} / \mathrm{min}$ using an extensometer and the secant method. The number of samples measured was $n=5$.

\subsection{Shore Hardness}

The Shore hardness tests were carried out according to DIN EN ISO 868 at room temperature and with a bearing weight of $5 \mathrm{~kg}$. A Shore D durometer was used and the maximum value was displayed after $15 \mathrm{~s}$ measuring time. For the hardness test, the measuring points were set in the parallel part of the test specimens. The number of samples measured was $n=5$.

\subsection{Impact Strength}

The impact tests were carried out on the HIT 5.5P from ZwickRoell using a $2 \mathrm{~J}$ impact pendulum on notched (A) specimens to DIN EN ISO 179-1. The number of specimens measured was $n=10$.

\section{Results and Discussion}

\subsection{Tensile Strength}

Initially, we investigated to which extent a correlation between the injection-molding parameters (Table 1), the fiber type and the fiber content in terms of tensile strength occurs. As a result, we found that the fiber content has a significant influence on the model description for the tensile strength. A linear correlation between the tensile strength in the region of interest and the fiber content was observed (Figure 3). A significant increase in strength was observed compared to unreinforced material $\left(5.31 \mathrm{~N} / \mathrm{mm}^{2}\right)$.

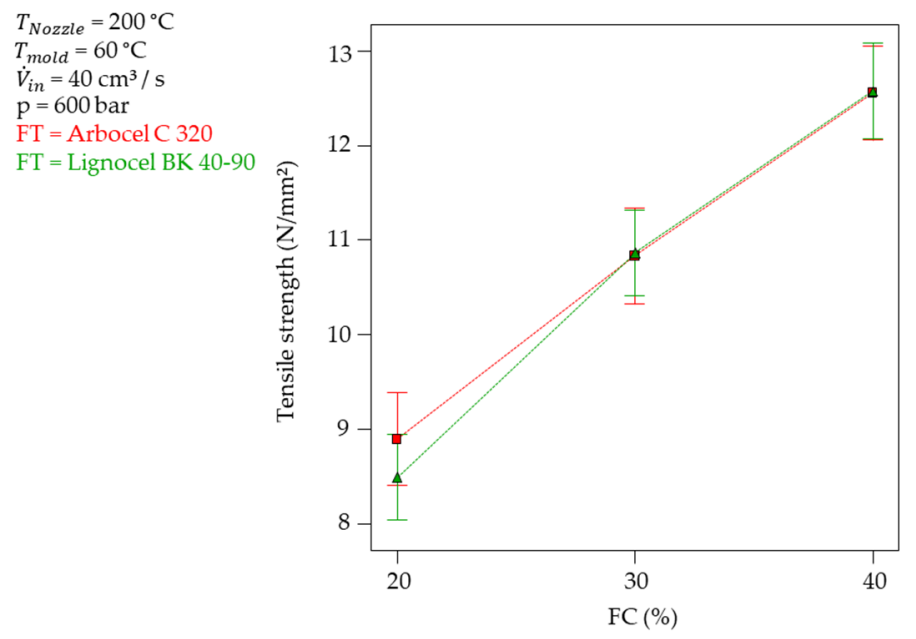

(a)

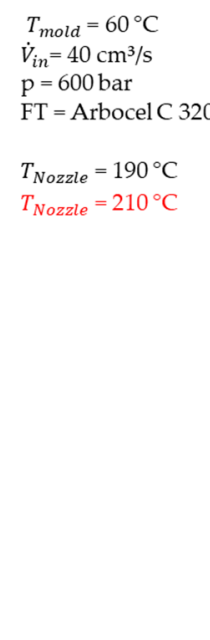

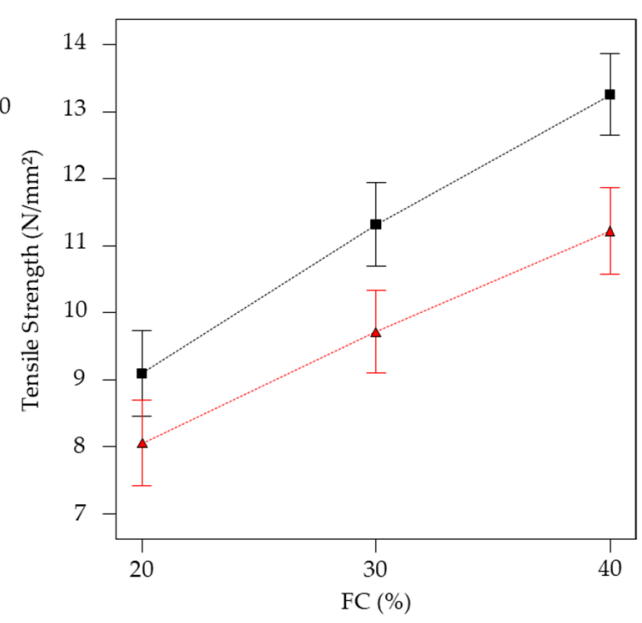

(b)

Figure 3. (a) Tensile strength of wood-filled TPU as a function of fiber content and fiber type. (b) Tensile strength of wood-filled TPU in dependence of temperature control.

This is in contradiction to the results of Diestel \& Krause. In their investigations, a decrease in tensile strength was initially found up to a fiber content of $35-\mathrm{wt}-\%$ and a subsequent increase in tensile strength between 35-wt- $\%$ and $70-w t-\%$ [27]. In their investigations on kenaf-filled TPU, El-Sheikeil et al. found a local tensile strength maximum at 30-wt-\%. Only the filling of TPU with cocoa shell showed similar effects compared to these studies [30-32]. Furthermore, our studies did not reveal any influence of fiber length for all fiber contents $(p>0.05$; Table 2$)$. 
Table 2. $p$-values of various test parameters for tensile strength.

\begin{tabular}{cccccc}
\hline & $\boldsymbol{T}_{\text {nozzle }}$ & $\boldsymbol{F C}$ & $\boldsymbol{p}$ & $\boldsymbol{T}_{\text {nozzle }} * \boldsymbol{p}$ & $\boldsymbol{F T}$ \\
\hline$p$-Value $(<0.05)$ & 0.0092 & 0.0049 & 0.0495 & 0.0474 & 0.4104 \\
\hline
\end{tabular}

This is in discrepancy to the investigations of Sälzer et al., who were able to demonstrate that an optimum with regard to tensile strength of WPC with a polypropylene matrix exists for fiber lengths of $500 \mu \mathrm{m}$ [19]. However, our results suggest that a good fiber-matrix adhesion exists irrespective of the fiber length. Next, we investigated to what extent the process parameters have an influence on the achievable tensile strength. In these investigations, the barrel temperature as well as the melt temperature had a significant influence on the maximal achievable tensile strength.

Temperature-sensitive wood fibers start to decompose at $200^{\circ} \mathrm{C}$ [8-14]. This is directly reflected in the achievable tensile strengths. In this respect, the highest tensile strengths were achieved at a processing temperature of $190{ }^{\circ} \mathrm{C}$ for all fiber contents. For a fiber reinforcement of $40-\mathrm{wt}-\%, 13.26 \mathrm{~N} / \mathrm{mm}^{2}$ and for a fiber reinforcement of $20-\mathrm{wt}-\%$ still $9.1 \mathrm{~N} / \mathrm{mm}^{2}$ tensile strength was achieved. With increasing temperature, the achievable tensile strength decreases significantly. This can be explained by the incipient decomposition of the wood fibers and subsequently released volatile organic components (VOC) of the wood fibers, which interact with the matrix material, resulting in vacuoles and hydrolytic matrix degradation due to water reposition in the cells of the wood fiber. A comparative analysis of tensile strength between $190^{\circ} \mathrm{C}$ and $210^{\circ} \mathrm{C}$ processing temperature as a function of fiber content reveals that the tensile strength is reduced with increasing fiber content. In this temperature range, the strength decreases by $11 \%$ for $20-\mathrm{wt}-\%$ compounds and by about $15 \%$ for $40-\mathrm{wt}-\%$ reinforced material. This supports our hypothesis that the decomposition of the wood fiber and the released organic components hydrolytically attack the matrix since it can be assumed that an increased fiber content also increases the amount of VOC. Furthermore, this dependency can be verified on the basis of the detected specimen weight. For low temperatures $\left(190^{\circ} \mathrm{C}\right)$, the specimen weight is significantly lower but the tensile strength is higher compared to the specimen weight at $200{ }^{\circ} \mathrm{C}$ and $210^{\circ} \mathrm{C}$, respectively (Figure 4). At higher temperatures, more mass can be injected and compacted into the cavity due to the lower viscosity but the decomposition fraction and VOC fraction is significantly higher, so the tensile strength is minimized. This decomposition fraction leads to a further reduction in viscosity. Considering the correlation of mass difference $\Delta \mathrm{m}$ and temperature levels at constant fiber content, this statement can be further substantiated, as the $\Delta \mathrm{m}$ increases with increasing fiber content.

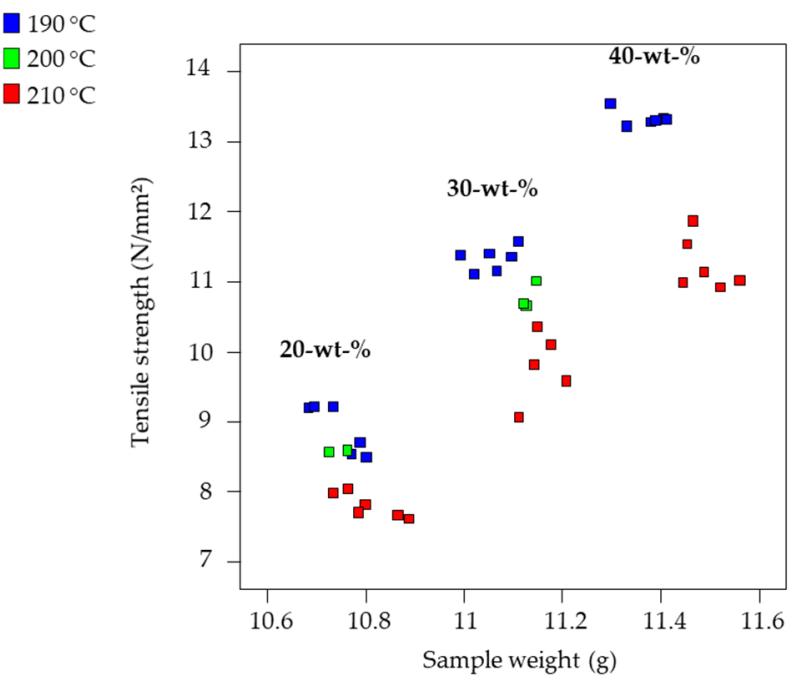

Figure 4. Correlation of tensile strength and specimen weight of wood-filled TPU. 
The correlation between holding pressure and tensile strength is well known and was not confirmed in these investigations. However, it is noteworthy that the interaction between cylinder temperature and holding pressure has a significant influence on tensile strength as well. For $190{ }^{\circ} \mathrm{C}$, only a slight influence of holding pressure can be demonstrated. For $210{ }^{\circ} \mathrm{C}$, it could be demonstrated that a high holding pressure leads to a reduction in strength. This is in discrepancy with the investigations of Schröder, who demonstrated a positive correlation between increased holding pressure and tensile strength [22]. The observed decrease in tensile strength in our studies can be explained by the higher proportion of emitted VOCs leading to increased vacuoles and a reduction in tensile strength. Furthermore, the decomposition of the matrix material proceeds more rapidly with increased pressure. These correlations were not found for materials with PP-based WPC, as investigated in Schröder's investigations.

\subsection{E-Modulus}

We also determined the stiffness of our WPCs in the tensile test. The test results showed an increase of the Young's modulus for both fiber types as a function of the fiber content with respect to unreinforced TPU $\left(6.38 \mathrm{~N} / \mathrm{mm}^{2}\right)$. The cylinder and mold temperature, which had a significant influence on the tensile strength, showed no unifiable effect on the Young's modulus (Table $3, p>0.05$ ).

Table 3. $p$-values of various test parameters for Young's modulus.

\begin{tabular}{ccccccc}
\hline & $F C$ & $\dot{V}_{\text {in }}$ & $\boldsymbol{F C} * \boldsymbol{T}_{\text {mold }}$ & $\dot{\boldsymbol{V}}_{\text {in }} * \boldsymbol{F C}$ & $\boldsymbol{T}_{\text {nozzle }}$ & $\boldsymbol{T}_{\text {mold }}$ \\
\hline$p$-Value $(<0.05)$ & $<0.0001$ & 0.0171 & 0.0054 & 0.0029 & 0.5067 & 0.4019 \\
\hline
\end{tabular}

For $20-w t-\%, 30-w t-\%$ and $40-w t-\%$, the Young's modulus was independent of the respective cylinder temperature (Figure 5). These findings are congruent with the results of Burgstaller et al., who showed that the Young's modulus is independent of melt or cylinder temperature [33].

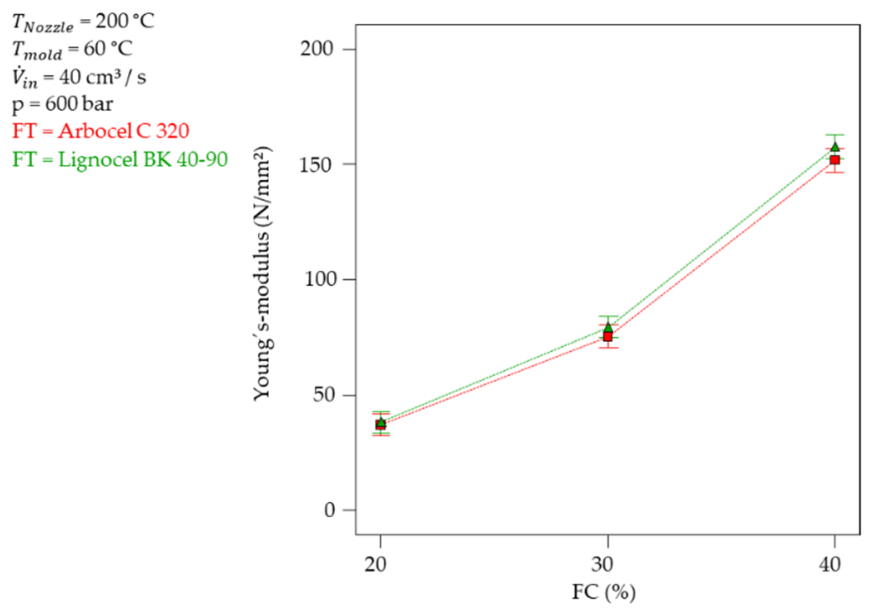

(a)

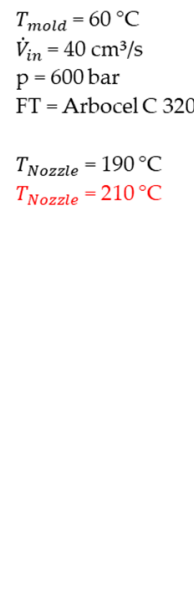
$\mathrm{p}=600 \mathrm{bar}$

$\mathrm{FT}=$ Arbocel $\mathrm{C} 320$

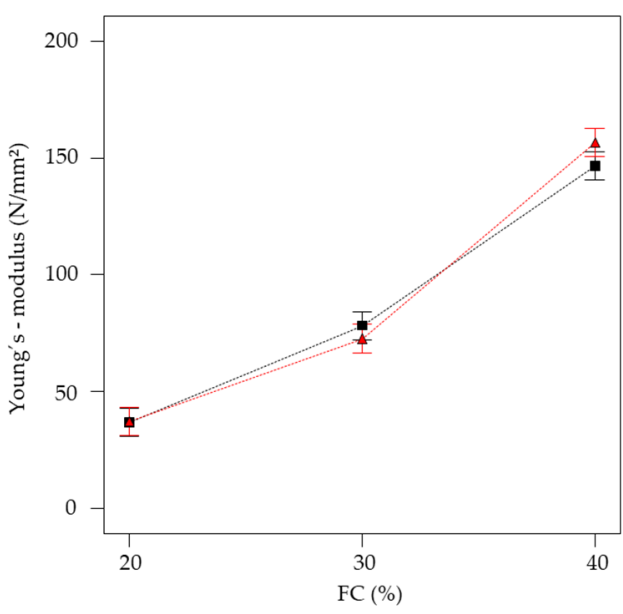

(b)

Figure 5. (a) Young's modulus of wood-filled TPU as a function of fiber content and fiber type. (b) Young's modulus of wood-filled TPU in dependence of temperature control.

\subsection{Notched Impact Strength}

Here, we focused on the extent to which the notched impact strength is influenced by the fiber reinforcement. Generally, plastics with fiber reinforcement tend to behave divergently in terms of notched impact strength. Burgstaller et al. showed that fiber reinforcement does not necessarily lead to a reduction in notched impact strength. How- 
ever, matrix materials with inherently high impact strength (FC 0-wt-\%) tended to show significant decreases in impact strength of the notched specimens, whereas the impact strength of materials with low impact strength ( $F C 0$-wt-\%) was only marginally affected by an increasing fiber content. The combination of stress concentration in the component and the increased stiffness due to fiber reinforcement was determined as the reason for the decrease in notched impact strength [33].

In the investigations of Diestel \& Krause, this statement could be verified for wood fiber reinforced TPU [27]. However, our results show that the notched impact strength is a function of the fiber content with a local maximum at 30-wt-\% (Figure 6, Table 4).

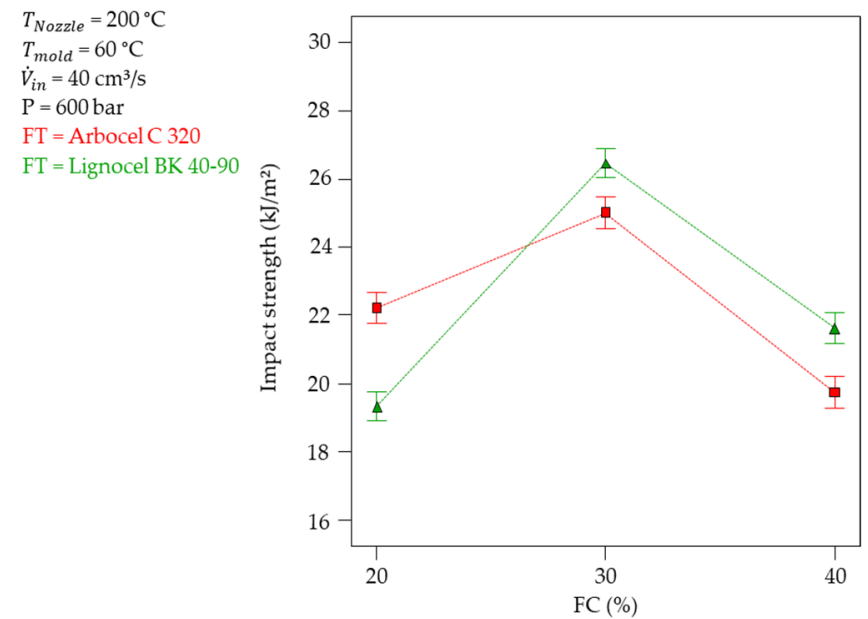

(a)

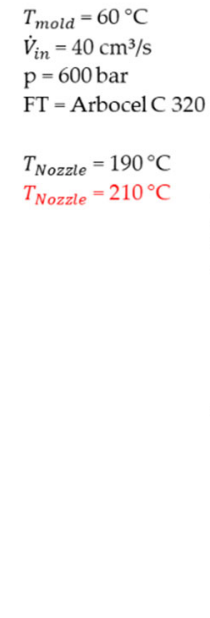

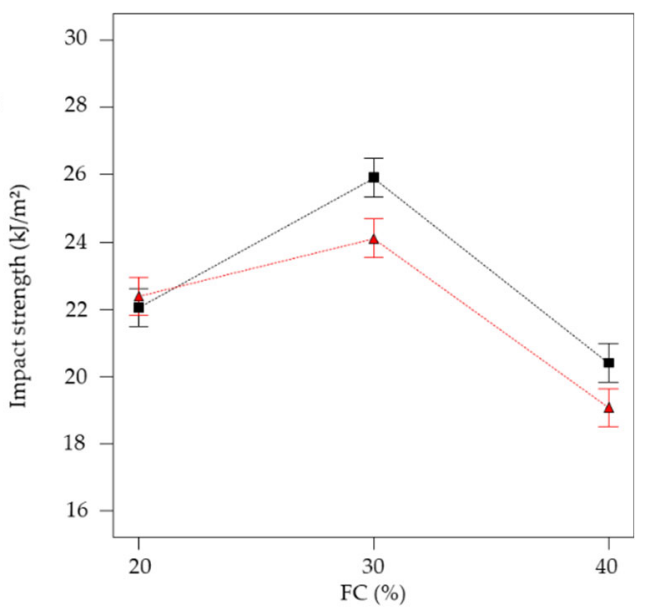

(b)

Figure 6. (a) Impact strength of wood-filled TPU as a function of fiber content and fiber type. (b) Impact strength of wood-filled TPU as a function of temperature control.

Table 4. $p$-values of various test parameters for notched impact strength.

\begin{tabular}{ccccccc}
\hline & $\boldsymbol{T}_{\text {nozzle }}$ & $\boldsymbol{F C}$ & $\boldsymbol{T}_{\text {nozzle }} * \boldsymbol{F C}$ & $\boldsymbol{F C} * \boldsymbol{F T}$ & $\boldsymbol{T}_{\text {mold }} * \boldsymbol{p}$ & $\boldsymbol{T}_{\text {mold }} * \boldsymbol{F C}$ \\
\hline$p$-Value $(<0.05)$ & 0.0022 & $<0.0001$ & 0.0089 & 0.0001 & 0.0051 & 0.0247 \\
\hline
\end{tabular}

This may be the result of adequate fiber-matrix adhesion, which leads to the force being introduced directly into the fibers during impact loading. Therefore, a high force is required to break the composite.

The decrease in notched impact strength at $40-\mathrm{wt}-\%$ can be explained by the high induced stress in the fiber material. Local stress peaks lead to increased crack propagation and fracture. Figure 6 illustrates that notched impact strength is a function of fiber length. In their investigations on WPC with a PP matrix, Sälzer et al. demonstrated that small particles tend to have higher notched impact strengths compared to larger particles [19]. The authors contribute these findings to more homogeneous distribution of the particles in the plastic matrix and a notch effect of long fibers. For a fiber content of $20-\mathrm{wt}-\%$, our results follow the findings of Sälzer et al. [19]. The shorter Arbocel fibers, however, exhibit an increased reinforcing effect compared to the Lignocel fibers. The higher specific surface area of the Arbocel fibers, which, in conjunction with good fiber-matrix adhesion, favors the introduction of the force into the matrix. For fiber contents above $20-\mathrm{wt}-\%$, our results follow the studies of Burgstaller et al. [14]. Increased impact energy can be applied with increasing fiber length because more energy is required for breaking out the fibers due to the larger fiber cross section. In our investigations, the combination of the effects of elastic deformation behavior and high cross-sectional area can serve as a reason for the higher impact strength of compounds with Lignocel fibers. Regarding the process parameters, it could be detected that the melt temperature has a significant influence on the notched 
impact strength induced by the VOC and the emerging decomposition. The decomposition products deteriorate the fiber-matrix adhesion, which accelerates fiber breakout in the notch region and, therefore, decreasing the notched impact strength. Furthermore, we found that the interaction of mold temperature/holding pressure and mold temperature/fiber content significantly influences the maximum achievable notched impact strength.

The mold temperature significantly influences the toughness of the WPCs with 20wt- $\%$ fiber content (Figure 7). With increasing temperature, the toughness decreased due to the fact that the sealing point is reached later and more material flows into the cavity, thus increasing compaction of the molecular chain, and fiber material leads to increased stiffness. This effect occurs for both types of fibers. If the holding pressure is increased in combination with the mold temperature, an opposite effect occurs. With increasing holding pressure, the notched impact strength increases for both fiber types. In this context, the matrix is pressed deeply into the porous fiber structure leading to increased fiber-matrix adhesion, which prevents fiber breakout and, therefore, the toughness increases. As with the other mechanical properties, a significant influence of the cylinder temperature was detectable. An increase in the cylinder temperature has a negative effect on the notched impact strength. The percentage of decomposed wood fibers and VOC have a negative effect on toughness. Furthermore, the fiber-matrix adhesion is deteriorated by evaporated organic components. As a result, force transmission under impact loading is reduced and breaking out of the fibers is more difficult.

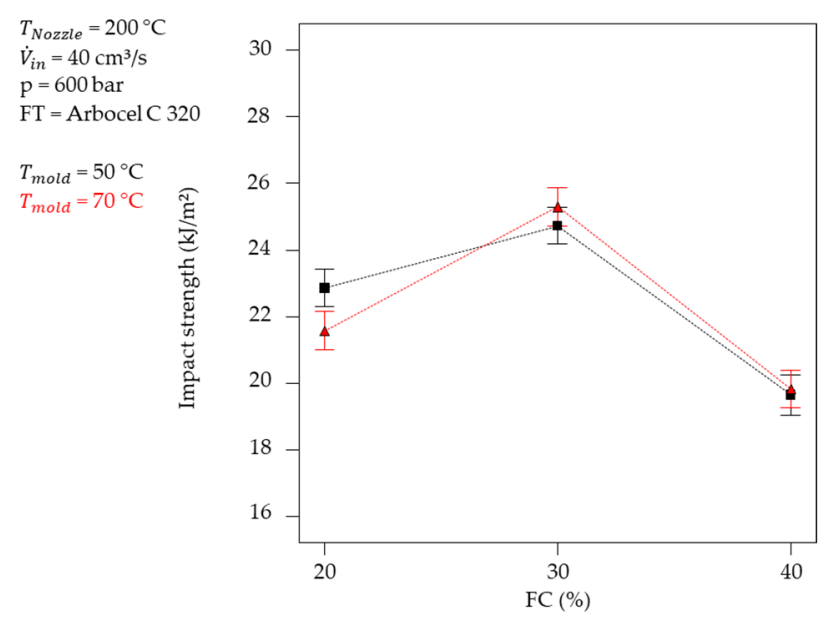

Figure 7. Detected notched impact strength of wood-filled TPU as a function of mold temperature.

\subsection{Shore Hardness}

Shore hardness tests were performed to detect the influence of fiber length, fiber content and process parameters on surface hardness. In the test area, it was found that an increasing fiber content leads to an increase in Shore hardness but the fiber type did not influence these parameters (Figure 8, Table 5). These results are in accordance with the studies of Diestel \& Krause [27] and can be justified by the reinforcing effect and compression of the fibers, leading to increased resistance to penetration. With increasing processing temperature, Shore hardness decreases for $20-\mathrm{wt}-\%$ fiber content, which can be explained by decomposition processes of the fibers and the matrix material.

Table 5. $p$-values of various test parameters for Shore hardness.

\begin{tabular}{ccccc}
\hline & $T_{\text {nozzle }}$ & FC & $T_{\text {nozzle }} *$ FC & $T_{\text {mold }} * \dot{V}_{\text {in }}$ \\
\hline$p$-Value $(<0.05)$ & 0.048 & $<0.0001$ & 0.0089 & 0.0051 \\
\hline
\end{tabular}




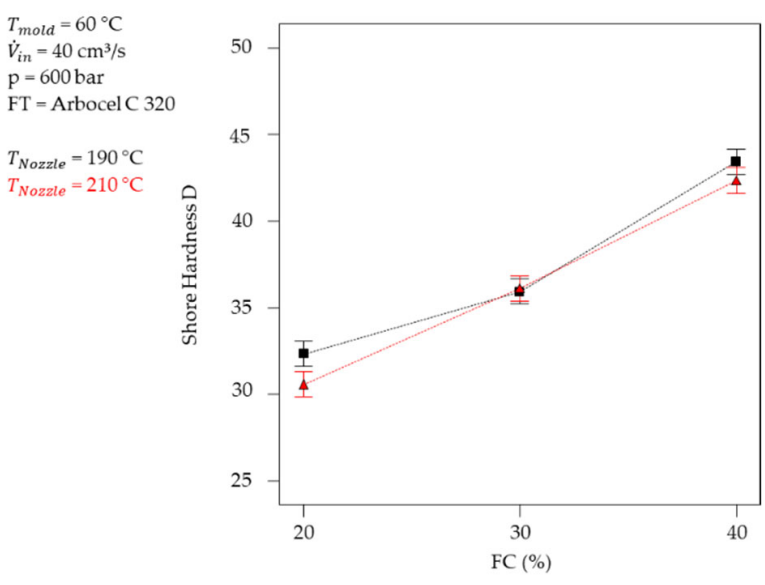

(a)

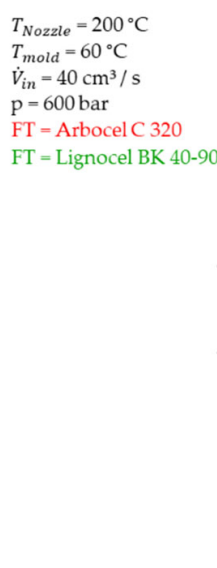

in $=40 \mathrm{~cm}^{3} / \mathrm{s}$

FT = Arbocel C 320

FT = Lignocel BK 40-90

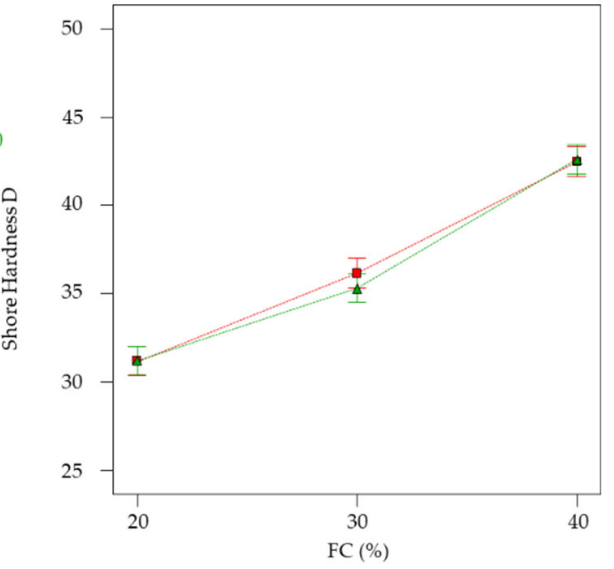

(b)

Figure 8. (a) Shore Hardness D of wood-filled TPU in dependence of temperature control. (b) Shore Hardness D of wood-filled TPU as a function of fiber content and fiber type.

\subsection{Elongation}

For elastomeric materials, the consideration of strain behavior is a vital issue. Our investigations illustrated that fiber reinforcement leads to a reduction in elongation, which is trivial during material embrittlement (Figure 9, Table 6). Notably, the significance of fiber type diminishes with increasing fiber content. For low-filled compounds, the elongation of WPC with Lignocel BK40/90 fibers is significantly lower than the elongation of WPC with Arbocel C320 fibers. This correlates with the reduced tensile strength (Figure 3). Therefore, we suggest that the fiber morphology has a significant impact in low-filled compounds. Small fiber lengths lead to a more homogeneous fiber distribution, accompanied with the generation of high tensile strength. Due to the short fiber length, the force conducts over a short distance, so that the fiber has little effect on the elongation. At longer fiber lengths, the fiber acts as a defect since the force transfer is primarily directed into the fiber and is not directly transferred back into the matrix. At higher fiber contents, this effect becomes less significant since stress peaks are generated directly between the fibers. Hence, elongation and slippage of the matrix on the fiber are not feasible. In addition, we observed a significant influence of the processing temperature. With increasing decomposition, an interphase forms between matrix and fiber, as well as further shrinkage due to VOC, which implies a reduction in elongation. This effect solely occurs with low-filled compounds.

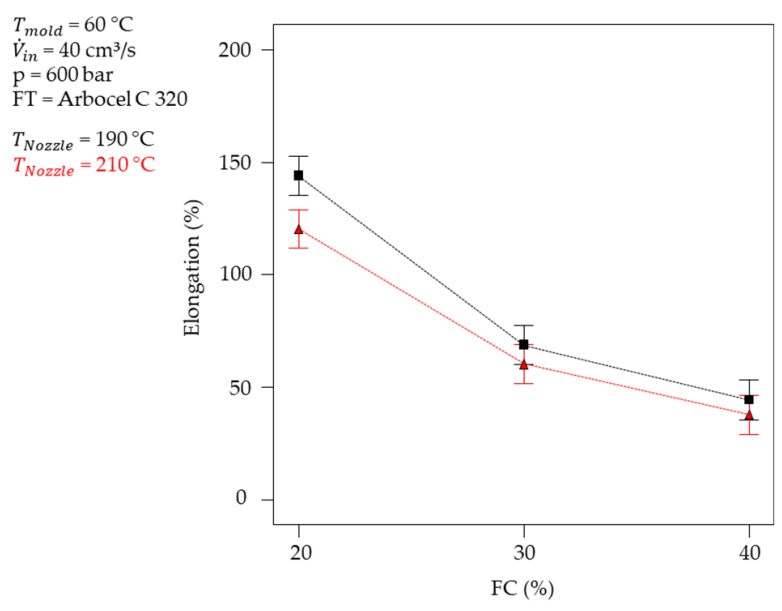

(a)

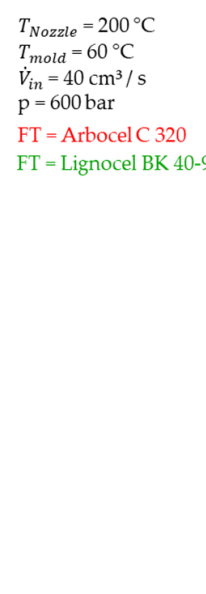

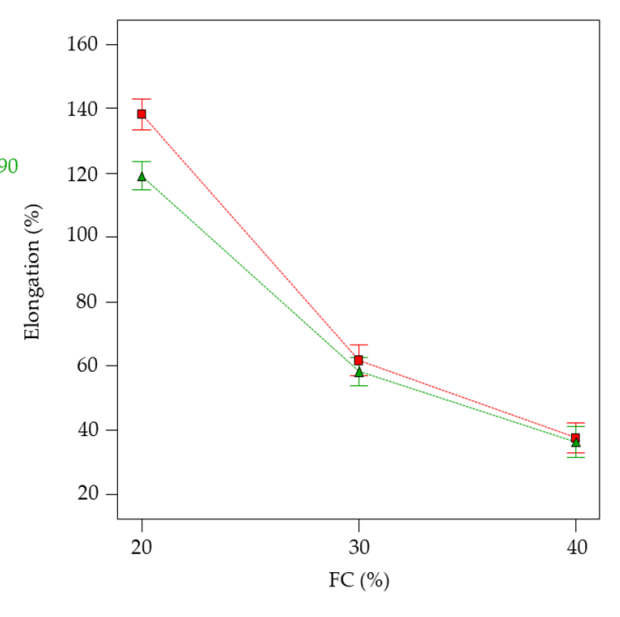

(b)

Figure 9. (a) Elongation of wood-filled TPU as a function of fiber content and temperature control. (b) Elongation of wood-filled TPU as a function of fiber content and fiber type. 
Table 6. $p$-values of various test parameters for strain.

\begin{tabular}{ccccc}
\hline & $\boldsymbol{T}_{\text {nozzle }}$ & FC & FT & FC $*$ C T \\
\hline$p$-Value $(<0.05)$ & 0.0085 & $<0.0001$ & 0.0174 & 0.0388 \\
\hline
\end{tabular}

\subsection{Process Parameters}

After analyzing the relevant mechanical parameters, a process analysis was performed. A correlation between injection volume, fiber content and nozzle temperature were detected. With increasing fiber content and increasing injection speed, a higher injection pressure is required (Figure 10, Table 7). When higher temperatures were applied, the required injection pressure decreased, irrespective of the fiber content and fiber type as well as the injection volume flow. With increased injection volume flow, the required injection pressure increased for all fiber contents.

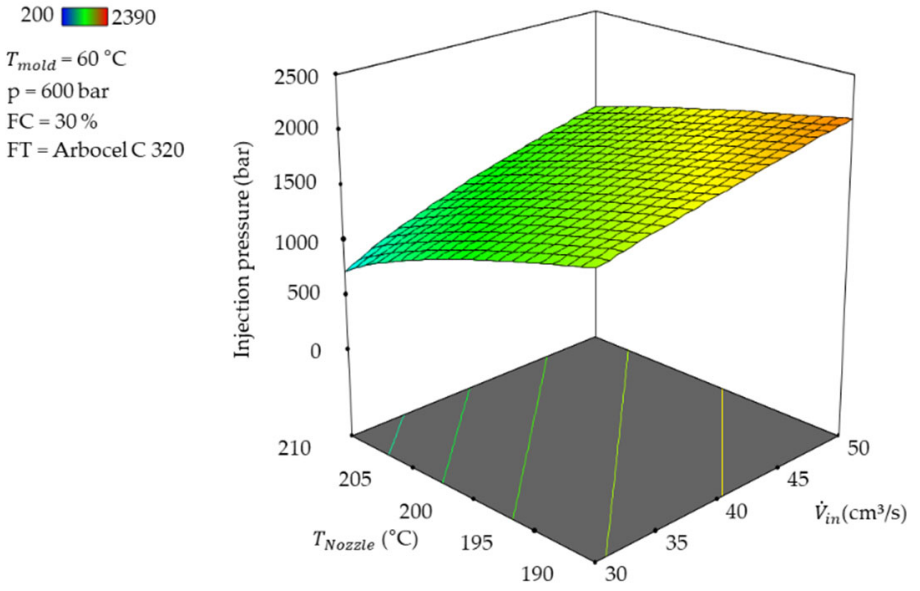

(a)

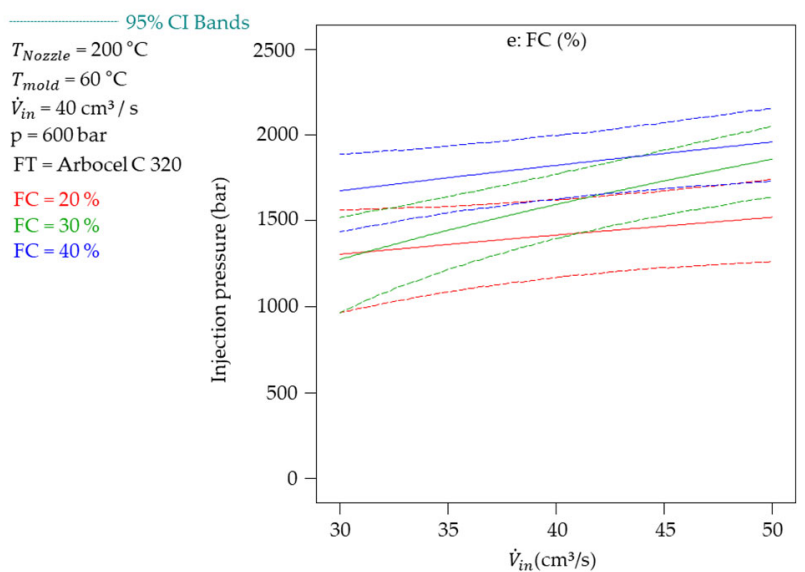

(b)

Figure 10. (a) Injection pressure of wood-filled TPU as a function of injection volume flow and temperature control. (b) Injection pressure of wood-filled TPU as a function of fiber content and injection volume flow.

Table 7. $p$-values of various test parameters for strain.

\begin{tabular}{cccc}
\hline & $\boldsymbol{T}_{\text {nozzle }}$ & $\boldsymbol{F C}$ & $\dot{\boldsymbol{V}}_{\text {in }}$ \\
\hline$p$-Value $(<0.05)$ & 0.0001 & $<0.0001$ & 0.001 \\
\hline
\end{tabular}

\section{Conclusions}

Here, we investigated a wood-filled ether-based TPU in the injection-molding process and analyzed its properties as a function of fiber content, fiber length and processing parameters. Based on these results, we propose the emergence of a new research field/market potential. It was found that a reinforcing effect can be achieved with increasing fiber content suggesting good fiber-matrix adhesion. In addition, there is a significant correlation between the achievable mechanical properties and the temperature control in the injectionmolding process. This can be attributed to increased fiber or matrix decomposition and an increased proportion of vacuoles due to VOC. With the analysis of the mechanical properties and the process analysis, a new field of research has been created in the material development of sustainable TPU. Potential applications of the newly investigated compounds as handles include, but are not limited to, sports equipment and rollers. Further investigations are projected with regard to abrasion resistance, dynamic mechanical behavior and the use of additional matrix materials. Moreover, the fiber-matrix adhesion will be evaluated in subsequent investigations in comparison with standard WPC. 
Author Contributions: Supervision, E.M.; Writing—original draft, M.R. All authors have read and agreed to the published version of the manuscript.

Funding: This Research was funded by the state of North Rhine Westphalia via the Forschungskolleg "Leicht-Effizient-Mobil" (LEM).

Conflicts of Interest: The authors declare no conflict of interest.

\section{References}

1. Kandemir, A.; Pozegic, T.R.; Hamerton, I.; Eichhorn, S.J.; Longana, M.L. Characterisation of Natural Fibres for Sustainable Discontinuous Fiber Composite Materials. Materials 2020, 13, 2129. [CrossRef]

2. Pickering, K.; Efendy, M.A.; Le, T. A review of recent developments in natural fibre composites and their mechanical perfor mance. Compos. Part A Appl. Sci. Manuf. 2016, 83, 98-112. [CrossRef]

3. Chan, C.M.; Vandi, L.-J.; Pratt, S.; Halley, P.; Ricahrdson, D.; Werker, A.; Laycock, B. Composites of Wood and Biodegrable Thermoplastics: A Review. Polym. Rev. 2018, 58, 444-494. [CrossRef]

4. Fitzgerald, A.; Proud, W.; Kandemir, A.; Murphy, R.J.; Jesson, D.A.; Trask, R.S.; Hamerton, I.; Longana, M.L. A Life Cycle Erngineering Perspective on Biocomposites as a Solution for a Sustainable Recovery. Sustainability 2021, 13, 1160. [CrossRef]

5. Carus, M.; Partanen, A. Bioverbundwerkstoffe-Naturfaserverstärkte Kunststoffe (NFK) und Holz-Polymer-Werkstoffe (WPC); Fachagentur Nachwachsende Rohstoffe e.V. (FNR): Gülzow-Prüzen, Germany, 2017.

6. Moritzer, E.; Hopp, M. The setting behavior of dispersion adhesives during bonding of Wood Plastic Composites (WPC). Weld. World 2017, 61, 1029-1038. [CrossRef]

7. Moritzer, E.; Hopp, M. Kleben von Wood-Plastic-Composites (WPC)-Material- und Oberflächenmodifizierung für spezielle Anwendungen. In Jahresmagazin Kunststofftechnik; Wissenschaftlicher Arbeitskreis der Universitätsprofessoren der Kunststofftechnik WAK: Stuttgart, Germany, 2015.

8. La Mantia, F.P. Effect of fillers on the properties of recycled polymers. In Macromolecular Symposia; WILEY-VCH Verlag: Weinheim, Germany, 2003; Volume 194, pp. 101-110.

9. Le Dugou, A.; Pillin, I.; Bourmaud, A.; Davies, P.; Baley, C. Effect of recycling on mechanical behaviour of biocompostable flax/poly (1-lactide) composites. Composites 2008, 39, 1471-1478. [CrossRef]

10. Winandy, J.E.; Stark, N.M.; Clemons, C.M. Considerations in Recycling of Wood-Plastic Composites. In Proceedings of the 5th Global Wood and Natural Fibre Composites Symposium, Kassel, Germany, 27-28 April 2004.

11. Boeglin, N.; Triboulot, P.; Masson, D. A feasibility study on boards from wood and plastic waste: Bending properties, dimensional stability and recycling of the board. In Holz Als Roh-und Werkstoff; Springer: Berlin, Germany, 1997; Volume 55, pp. 13-16.

12. Schirp, A.; Hellmann, A.; Plinke, B.; Mauruschat, D. Stoffliches Recycling von Wood-Polymer Composites (WPC, HolzKunststoff-Verbundwerkstoffen). In 4. Fachtagung Umweltschutz in der Holzwerkstoffindustrie; Universität Göttingen: Göttingen, Germany, 2014.

13. Sommerhuber, P.F. Resource Efficiency of Wood-Plastic Composites. Ph.D. Thesis, University of Hamburg, Hamburg, Germany, 2018.

14. Burgstaller, C. Material Recycling of WPC. In Proceedings of the 4th German WPC-Congress, Cologne, Germany, 13-14 December 2011.

15. Gandini, A.; Belgacem, M.N. Modified cellulose fibers as reinforcing fillers for macromolecular matrices. In Macromolecular Symposia; WILEY-VCH Verlag: Weinheim, Germany, 2005; Volume 221, pp. 257-270.

16. Lu, J.Z.; Wu, Q.; Negulescu, I. Surface and interfacial characterization of wood-PVC composites: Thermal and dynamic mechanical properties. Wood Fibre Sci. Soc. Wood Sci. Technol. Monona 2004, 36, 500-510.

17. d'Agostino, R. Plasma Deposition, Treatment and Etching of Polymers; Academic Press Inc.: New York, NY, USA, 1990.

18. Hebeish, A.; Guthrie, J.T. The Chemistry and Technology of Cellulosic Copolymers; Springer: Berlin, Germany, 1981.

19. Sälzer, P.; Feldmann, M.; Heim, H.-P. Wood-Polypropylene Composites: Influence of Processing on the Particle Shape and Size in Correlation with the Mechanical Properties Using Dynamic Image Analysis. In Proceedings of the International Polymer Processing XXXIV, Taipei, Taiwan, 21-25 May 2018; Volume 32, pp. 677-687.

20. Siwek, S.; Oktaee, J.; Grasselt-Gille, S.; Wagenführ, A. Influence of different wood flour fractions on the mechanical properties of injection molded WPC with cellulose propionate. Eur. J. Wood Wood Prod. 2018, 76, 499-507. [CrossRef]

21. Radovanovic, I. Verarbeitung und Optimierung der Rezeptur von Wood Plastic Composites (WPC). Ph.D. Thesis, Universität Osnabrück, Osnabrück, Germany, 2007.

22. Schröder, C. Verfahrenstechnische Entwicklung zum Hinterspritzen von Echtholzfurnieren mit Wood-Plastic-Composites (WPC). Ph.D. Thesis, Universität Paderborn, Paderborn, Germany, 2013.

23. Hristov, V.; Takács, E.; Vlachopoulos, J. Surface tearing and wall slip phenomena in extrusion of highly filled HDPE/wood flour composites. Polym. Eng. Sci. 2006, 46, 1204-1214. [CrossRef]

24. Kim, J.K.; Pal, K. Recent Advances in the Processing of Wood-Plastic Composites; Springer: Berlin/Heidelberg, Germany, 2010.

25. Nagatani, A.; Endo, T.; Hirotsu, T.; Furukawa, M. Preparation and Properties of Cellulose-Olefinic Thermoplastic Elastomer Composites. J. Appl. Polym. Sci. 2005, 95, 144-148. [CrossRef]

26. Kunihiro, A.; Kaneko, S.; Matsumoto, K.; Nagatani, A.; Tanaka, T.; Arao, Y. Improvement of The Functionalities of Natural Rubber/Cellulose Composites Using Epoxidized Natural Rubber. Adv. Mater. Res. 2015, 1110, 51-55. 
27. Diestel, S.; Krause, A. Wood-based composites with thermoplastic polyurethane as matrix polymer. J. Appl. Polym. Sci. 2018, 135, 46344. [CrossRef]

28. Kilinc, K.; Kanubr, Y.; Tayfun, Ü. Mechanical, thermo-mechanical and water uptake performance of wood flour filled polyurethane elastomer eco-composites: Influence of surface treatment of wood flour. Holzforschung 2019, 73, 401-407. [CrossRef]

29. Mengeloglu, F.; Cavus, V. Preparation of Thermoplastic Polyurethane-based Biocomposites through Injection Molding: Effect of the Filler Type and Content. Bioresour. Raleigh 2020, 15, 5749-5763. [CrossRef]

30. El-Shekeil, Y.A.; Sapuan, S.M.; Algrafi, M.W.K. Effect of fiber loading on mechanical and morphological properties of cocoa pod husk fibers reinforced thermoplastic polyurethane composites. Mater. Des. 2014, 64, 330. [CrossRef]

31. El-Shekeil, Y.A.; Sapuan, S.M.; Haron, M. Effect of Fiber Loading on Tensile Properties of Coca Pod Husk Fibers Reinforced Thermoplastic Polyurethane Composites. Appl. Mech. Mater. 2014, 25, 606.

32. El-Shekeil, Y.A.; Sapuan, S.M.; Haron, M. Optimization of Processing Parameters and Fiber Content of Cocoa Pod Husk Fiber-Reinforced Thermoplastic Polyurethane Composites by Taguchi Method. Appl. Mech. Mater. 2014, 564, 34. [CrossRef]

33. Burgstaller, C.; Bandion, C.; Reisecker, V.; Schaffler, G.; Göseweiner, A.; Ladner, H.; Moser, K.; Edlinger, B.; Hartl, F.; Maticka, C.; et al. Neue Wertschöpfung aus Wood Plastic Composites durch Einsatzmöglichkeiten für Spritzgussanwendungen, Report, Wels. 2011. Available online: https://www.nachhaltigwirtschaften.at/resources/fdz_pdf/endbericht_1103_wpc_ spritzgussanwendungen.pdf (accessed on 17 September 2021). 